\title{
USO DA ULTRA-SONOGRAFIA EM FÊMEAS SUÍNAS SUBMETIDAS A ACASALAMENTO NATURAL OU INSEMINAÇÃO ARTIFICIAL
}

\author{
ABUD, Sara Felícia Assaff ${ }^{1}$ \\ AGOSTINHO, Juliana Maria Avanci ${ }^{1}$ \\ LÉGA, Elzylene ${ }^{2}$ \\ MARTINS, José Reinaldo ${ }^{1}$ \\ SLIUZAS, Gianne Regina dos Santos $^{1}$
}

Recebido em: 2009-02-06

Aprovado em: 2009-04-29

Issue DOI: $10.3738 / 1982.2278 .167$

RESUMO: O desempenho reprodutivo tem grande importância na eficiência econômica da atividade suinícola. Dentro desse contexto, a suinocultura moderna conta com grandes avanços na área reprodutiva destacando-se o uso da inseminação artificial, acasalamentos naturais controlados e até mesmo o diagnóstico precoce de gestação através da ultra-sonografia. O presente trabalho teve como objetivo utilizar a ultra-sonografia no diagnóstico de gestação de fêmeas suínas, determinando o melhor período para sua aplicação, e ainda avaliar a eficiência reprodutiva na utilização da inseminação artificial e acasalamento natural. Foram realizados exames ultrasonográficos transabdominais em ambos os antímeros de cada animal. O tempo mínimo de gestação das fêmeas suínas para diagnóstico realizado por ultra-sonografia foi de 20 dias, mostrando ser um exame rápido, de alta acurácia, podendo ser utilizado como método auxiliar para melhorar a eficiência reprodutiva nesta espécie.

Palavras-chave: Inseminação artificial. Suínos. Ultra-sonografia.

SUMMARY: The reproductive performance is of great importance in the economic efficiency of pig activity. Within this context, the modern pig farming has great advances in reproductive highlighting the use of artificial insemination, natural mating, and even controlled the early diagnosis of pregnancy by ultrasound. This study aimed to use ultrasound in the diagnosis of pregnancy of sows, determining the best period for its implementation, and evaluate the reproductive efficiency in the use of artificial insemination and natural mating. Were carried out ultrasound scans in both transabdominais antimere of each animal. The minimum period of gestation of sows for diagnosis performed by ultrasound was 20 days, showing to be a quick look, high accuracy and can be used as an auxiliary method to improve reproductive efficiency in this species.

Keywords: Artificial insemination. Pigs. Ultrasonography.

$1 \quad$ Graduanda do Curso de Medicina Veterinária. FE/FAFRAM. Ituverava.

2 Docente do Curso de Medicina Veterinária. FE/FAFRAM. Ituverava. 


\section{INTRODUÇÃO}

Uma parcela importante da eficiência econômica da atividade suinícola é atribuída ao desempenho reprodutivo (FERREIRA et al., 2005). Nesse contexto, a inseminação artificial surge como uma alternativa para melhorar a eficiência reprodutiva e a produtividade, oferecendo novas perspectivas tecnológicas à produção animal (CANDINI et al., 2000).

A chave do sucesso do programa de inseminação artificial está no correto diagnóstico do estro, fazendo-se necessário, para este fim, a presença de um macho adulto, com características específicas (OLIVEIRA JUNIOR, 2008).

$\mathrm{Na}$ Suinocultura moderna, as fêmeas acasaladas ou inseminadas podem ser submetidas a métodos precoces de diagnóstico de gestação, a fim de separar fêmeas gestantes e não gestantes, para que estas últimas sejam novamente acasaladas, tratadas ou descartadas, tornando possível o retorno mais eficiente do capital empregado na criação (HUNTING, 1972). Com isso, a procura por métodos mais confiáveis, precisos e precoces de diagnóstico de gestação tem aumentado, sendo importante na redução de custos e no retorno econômico com a resolução de problemas de fertilidade (O'REILLY, 1976; VIANA et al., 2001). O método escolhido deve ser acurado, barato, rápido, seguro e fácil de ser realizado, podendo ser aplicável precocemente durante o período gestacional, além de ser altamente específico e sensível (HUNTING, 1972; VIANA et al., 2001). Vários são os métodos para o diagnóstico precoce da gestação: palpação retal, biópsia vaginal, testes hormonais, testes hematológicos e ultra-sonografia (HUNTING, 1972; CAVALCANTI et al., 1983; INABA et al., 1983; TONIOLLI et al., 1989; SILVA et al., 2001).

Desta forma, o presente trabalho teve como objetivo utilizar a ultra-sonografia no diagnóstico de gestação de fêmeas suínas, bem como determinar o melhor período de sua aplicação, a fim de avaliar a eficiência reprodutiva da utilização da inseminação artificial.

\section{REVISÃO DA LITERATURA}

Em qualquer sistema de produção animal, a eficiência reprodutiva é a principal meta econômica. Na suinocultura, ela é representada pelo número de leitões desmamados por porca por ano. Atentando-se para um bom manejo de marrãs, um desempenho excelente poderá ser conseguido durante a vida útil das porcas no plantel de reprodução. Entretanto, estas metas só poderão ser atingidas através do conhecimento de características fisiológicas das fêmeas das linhas maternas contemporâneas. O controle da condição corporal ao acasalamento, traduzindo na massa corporal e não "gordura", e da maturidade sexual das marrãs selecionadas para integrar o plantel de reprodução pode maximizar o desempenho das fêmeas de primeiro parto e, consequentemente, melhorar o desempenho reprodutivo do plantel durante a vida útil dessas fêmeas como matrizes (ALMEIDA; FOXCROFT, 2006).

Assim sendo, nos processos de ampliação de plantéis ou mesmo na implantação de 
novas unidades de produção, a marrã representa a unidade fundamental dos sistemas produtivos. Não somente o resultado imediato dos plantéis recém-estabelecidos será afetado, mas também a produtividade futura dos mesmos. Esta interferência resulta da correlação positiva entre o desempenho da fêmea ao primeiro parto com sua produtividade subsequente e com a eficiência global do rebanho (FOXCROFT; AHERNE, 2000). As marrãs merecem uma atenção especial no rebanho de reprodução, pois elas também contribuem desproporcionalmente para o total de dias improdutivos devido à menor taxa de fertilidade (FONTES et al., 2007).

\subsection{DETECÇÃO DO CIO}

O cio ou estro caracteriza-se por uma série de transformações no comportamento da marrã e/ou porca, fazendo com que a fêmea aceite o macho (OBERLENDER et al., 2008).

O melhor momento para efetuar o acasalamento é a fase em que a fêmea aceita a presença do macho, permitindo a cópula, caracterizando ações comportamentais próprias da fase do cio propriamente dito. Estudos demonstram que o momento mais apropriado para o acasalamento natural ou inseminação artificial em porcas é 12 horas após o início dos sinais de estro e, em marrãs, é no momento da detecção dos primeiros sinais (SILVA, et al., 2008).

A presença do macho reprodutor é uma ferramenta eficaz no processo de diagnóstico de cio, pois na sua presença, a fêmea recebe estímulo que auxilia na exteriorização dos sinais. $\mathrm{O}$ macho usado para este fim deve receber treinamento, ser dócil e ter características de cachaço, ou seja, apresentar odor próprio e intensa salivação, pois é na saliva que se encontra a maior concentração de ferormônios, e estes atuam diretamente no ciclo estral da porca. O diagnóstico de cio deve ser realizado no mínimo duas vezes ao dia, sempre nos horários mais frescos, e se inicia com a passagem do macho diante das fêmeas vagarosamente, dando tempo para que estas reconheçam sua presença. Assim, as fêmeas em período fértil produzem os hormônios responsáveis pelos sinais externos de cio que atraem o macho. Logo após, o macho é separado das fêmeas e aquelas que manifestaram interesse por ele são submetidas ao teste de monta ou teste lombar (Figura 1), ou seja, faz-se uma pressão na região lombar em cada fêmea, montando-a e verificando sua tolerância. As fêmeas que apresentarem positividade a este reflexo devem ser inseminadas imediatamente e após cada 12 ou 24 horas, dependendo do manejo praticado na granja com base no intervalo entre desmame e cio (OLIVEIRA JUNIOR, 2008). 


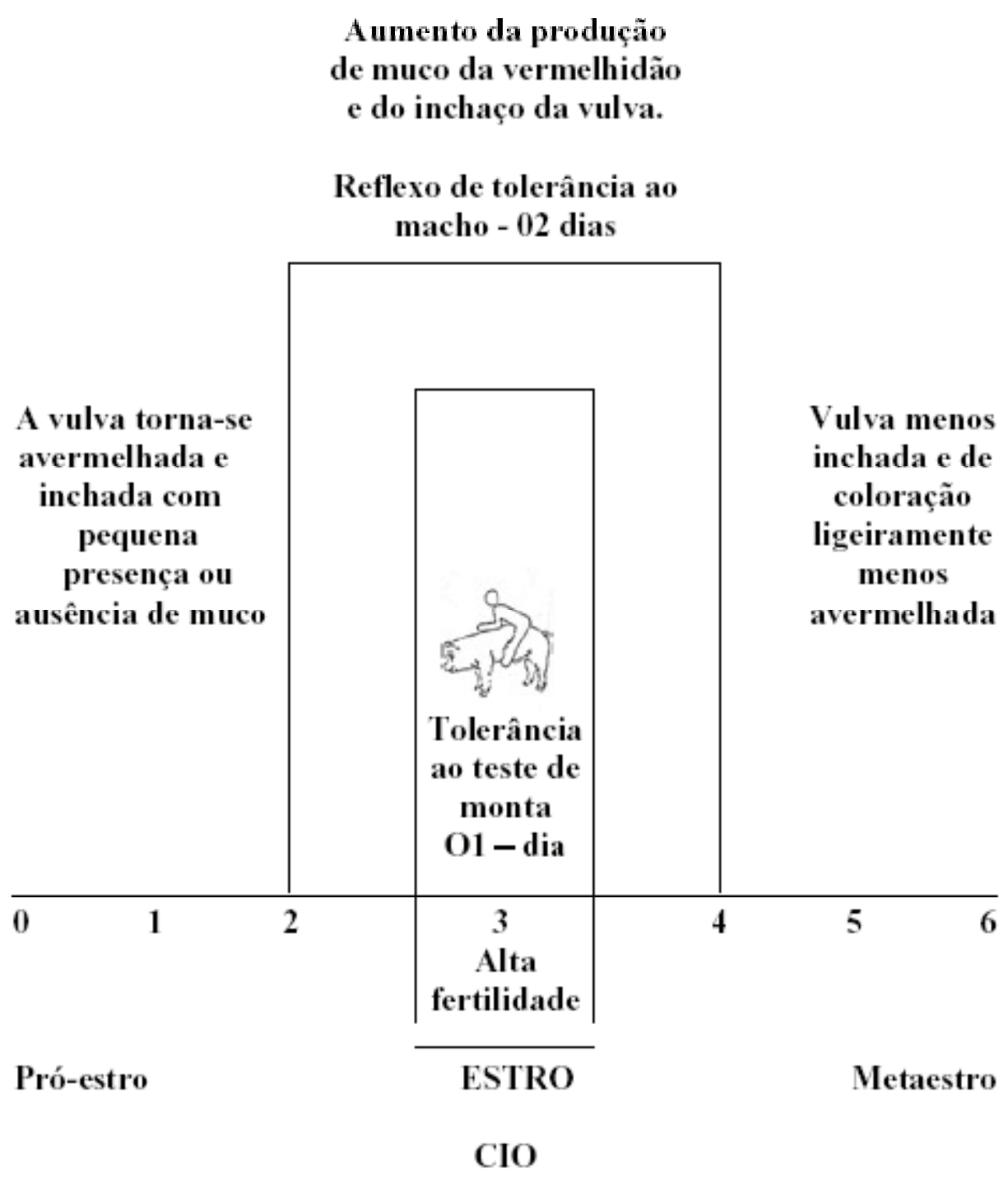

FIGURA 1 - Momento ideal para se realizar o acasalamento natural ou inseminação artificial.

\subsection{ACASALAMENTO NATURAL}

Na espécie suína, durante a monta natural, o ejaculado é depositado no canal cervical passando rapidamente para o lúmen uterino.

De acordo com Silva et al. (2008), o acasalamento ou monta natural é divida em quatro modalidades:

a) Acasalamento extensivo: é aquele praticado em criações extensivas, quando todos os suínos, entre eles cachaços, matrizes e leitões, ficam soltos juntos, sem controle algum sobre a reprodução e criação de leitões, ou seja, sem acompanhamento técnico. Não é o sistema mais indicado.

b) Acasalamento a campo ou à solta: é aquele na qual o criador solta o cachaço junto com as matrizes em pré-gestação por um mês aproximadamente, deixando que o reprodutor realize o acasalamento sem a interferência do homem. É uma modalidade que apresenta alguma 
tecnificação, pois o criador já escolhe o reprodutor a usar, porém não se sabe quais porcas foram acasaladas. Outro problema é que o cachaço vai praticar várias coberturas (em uma ou mais porcas) num pequeno espaço de tempo, desgastando-se e passando a ejacular espermatozóides imaturos e, como consequência, diminuindo a viabilidade dos mesmos. É um sistema de manejo pouco utilizado.

c) Acasalamento parcialmente controlado: é aquele em que o criador tem uma criação tecnificada. Quando uma porca entra no cio, é colocada junto com o reprodutor durante o dia ou durante a noite, permanecendo juntos por mais ou menos 12 horas. Porém, neste caso, o macho pode cobrir a porca por várias vezes no início, desgastando-se e, se a ovulação ocorrer mais tarde, os espermatozóides estarão imaturos e com baixa viabilidade, prejudicando assim, a fertilidade.

d) Acasalamento controlado ou dirigido: ocorre quando o criador tem uma criação tecnificada e, na época do cio, leva a porca à baia do varrão ou á baia de cobertura e acompanha a reprodução auxiliando o reprodutor, se necessário. Após a cópula, o criador retira a matriz da presença do macho e a conduz até á baia de pré-gestação.

Mesmo no acasalamento natural, é importante que se faça a avaliação periódica do sêmen para melhorar a eficiência reprodutiva do plantel.

\subsection{INSEMINAÇÃO ARTIFICIAL}

A inseminação artificial na espécie suína foi empregada inicialmente na década de 1930 no Japão e na Rússia, ocorrendo, a partir de então, uma evolução lenta e gradativa do uso dessa biotécnica em diferentes países, principalmente, europeus. Embora haja relatos do emprego dessa técnica no Brasil no final da década de 1940, somente na década de 1970 foram implantados os primeiros programas comerciais da IA na espécie suína (BORTOLOZZO et al. 2008), tomando um grande impulso, por constituir um método de reprodução de grande eficiência econômica.

$\mathrm{Na}$ atualidade, esta técnica é praticada em todo o mundo. No Brasil, a inseminação artificial teve uma grande expansão a partir de 1975, apesar dos primeiros estudos terem sido desenvolvidos a partir de 1959 (OBERLENDER, et al. 2008).

A introdução da inseminação artificial no manejo reprodutivo traz grande número de benefícios, tanto econômicos quanto sanitários e zootécnicos. Dentre as vantagens da IA, destacam-se melhoria do nível genético da criação pela introdução de reprodutores de alto valor zootécnico; redução do número de reprodutores necessários para atender o plantel; redução dos custos de manejo; maior segurança sanitária; controle mais preciso da eficiência reprodutiva do plantel e detecção precoce de falhas reprodutivas relacionadas ao macho. No entanto, algumas limitações devem ser consideradas para a obtenção de índices satisfatórios como qualificação dos funcionários, bom manejo geral e reprodutivo e necessidade de proximidade da central 
de inseminação artificial ou sua implantação na granja devido à curta viabilidade do sêmen resfriado (CANDINI et al., 2000).

\subsection{DIAGNÓSTICO DE GESTAÇÃO}

A utilização de um método precoce de diagnóstico de gestação é importante na suinocultura (HUNTING, 1972). Uma fêmea não-prenhe apresenta um maior número de dias improdutivos e tal fato implica em aumento no custo de produção da granja (VIANA et al., 2001). Assim, verificando a existência de fêmeas não-prenhes precocemente, as mesmas podem ser acasaladas, inseminadas novamente ou tratadas, tornando-se produtivas em um menor período de tempo (HUNTING, 1972).

Entre os métodos de diagnóstico de gestação, a ultra-sonografia transabdominal se destaca na suinocultura moderna. Com a antecipação do diagnóstico via ultra-som, é possível tomar decisões precoces, evitando perdas e possibilitando agregar valor à produção (ULTRASONOGRAFIA[...]; 2008). A técnica de ultra-sonografia tem como principais vantagens a precocidade, a rapidez e a facilidade de realização (VIANA et al. 2001).

Durante a gestação, mortes embrionárias ou fetais são comuns e, muitas vezes, se traduzem por retornos regulares ou irregulares ao cio. No entanto, algumas vezes esse cio não é detectado ou até mesmo não é manifestado pela fêmea. É nesse momento que a ultrasonografia assume seu papel diferencial no processo de produção. Antecipar o diagnóstico ou até mesmo confirmar suspeitas pode ser o diferencial na manutenção do produtor na atividade, pois falhas no processo de produção que, muitas vezes, não são visualizadas ou diagnosticadas, acabam determinando o fim de uma atividade que é lucrativa. Os exames devem ser rotineiros na propriedade, sendo recomendado que todas as fêmeas sejam submetidas à ultra-sonografia a partir dos 20 dias após a inseminação ou acasalamento. Com o método da ultra-sonografia, é possível planejar melhor a propriedade quanto à previsão de receitas, pelo acompanhamento das gestações. O resultado das prenhezes é antecipado, o que facilita o planejamento do uso das instalações (ULTRA-SONOGRAFIA[...], 2008).

\section{MATERIAL E MÉTODOS}

\subsection{ANIMAIS}

O presente trabalho foi realizado nas dependências do Setor de Suinocultura da Faculdade Dr. Francisco Maeda, no município de Ituverava-SP; para tanto foram utilizados quatro machos e 24 fêmeas, totalizando 28 animais, das raças Pietran, Landrace e Large White, sendo duas fêmeas e um macho da primeira, 21 fêmeas e dois machos da segunda e um macho da terceira, com pesos médios de $150 \mathrm{~kg}$ para as marrãs, de $260 \mathrm{~kg}$ para as matrizes e de $280 \mathrm{~kg}$ para os

Nucleus Animalium, v.1, n.1, maio 2009 
machos.

Das fêmeas utilizadas, 12 foram submetidas a acasalamento natural e 12 foram submetidas à inseminação artificial, sendo as primeiras com uma média de 2,5 anos e as outras com idade média de oito meses. Os machos utilizados tinham em média dois anos de idade.

\subsection{MANEJO}

Os animais foram mantidos em baias individuais (Figura 02), separados por idade, sendo a alimentação oferecida de acordo com cada fase: na desmama foi fornecida ração para fase em lactação à vontade; para as marrãs foi oferecida ração de crescimento, sendo que 20 dias antes do cio forneceu-se ração de lactação na proporção de $3 \mathrm{~kg}$ por dia; durante 30 dias após o acasalamento, as fêmeas receberam 1,8 a 2kg de ração ao dia. De 31 a 60 dias, as fêmeas receberam 2,2 a 2,4kg por dia; de 61 a 85 dias, 2,5 a 2,8kg por dia; de 86 dias até o parto, 3 a $3,5 \mathrm{~kg}$ por dia de ração lactação até o desmame.

Os animais foram vacinados contra rinite e Escherichia coli, aos 85 dias antes do parto, com reforço aos 100 dias, quando também foram submetidos à vermifugação.

As baias receberam proteção de luz com cortinas e arborização (Figura 03), para evitar estresse térmico dos animais.

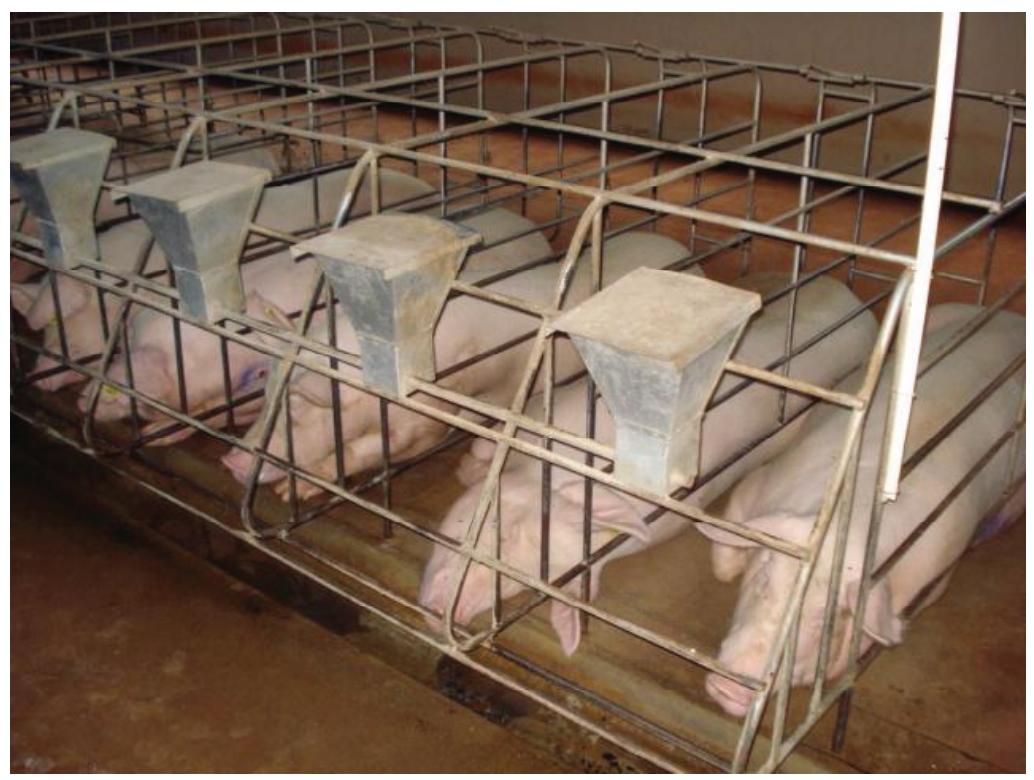

FIGURA 02: Animais mantidos em baias individuais. Setor de Suinocultura - Faculdade Dr. Francisco Maeda (FAFRAM) - Ituverava-SP, 2008. 


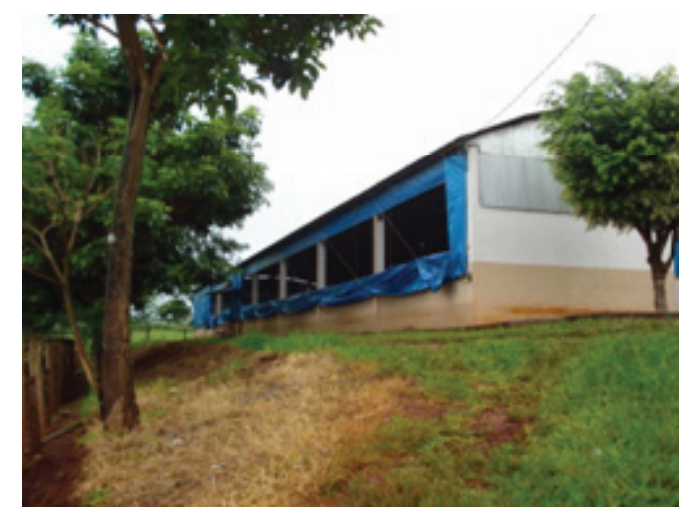

FIGURA 03: Galpão de alojamento dos animais protegido com cortinas em área arborizada. Setor de Suinocultura - Faculdade Dr. Francisco Maeda (FAFRAM) - Ituverava-SP, 2008.

\subsection{TIPO DE ACASALAMENTO}

\subsubsection{ACASALAMENTO NATURAL}

Após a passagem do macho pelas baias das fêmeas, para estimulá-las a liberar ferormônio, e posteriormente realizado o teste lombar (Figura 04), a fêmea em cio foi levada até a baia do macho, onde foi feito o acasalamento, no mínimo duas vezes, no intervalo de 24 horas.

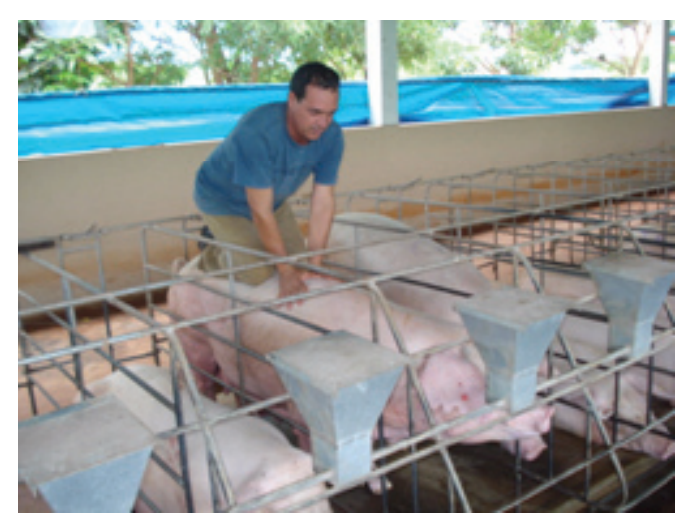

FIGURA 04: Teste lombar realizado para detecção da fêmea em estro. Setor de Suinocultura - Faculdade Dr. Francisco Maeda (FAFRAM) - Ituverava-SP, 2008.

\subsubsection{COLHEITA E AVALIAÇÃO DO SÊMEN}

O sêmen de cada cachaço foi colhido a cada cinco dias, no período da manhã, sempre com a temperatura ambiente inferior a $22^{\circ} \mathrm{C}$.

A colheita do sêmen foi realizada pelo método de massagem com mãos devidamente enluvadas e ajuda de manequim móvel. Os cachaços foram primeiramente higienizados em sua 
região prepucial e no momento da colheita, os primeiros jatos de sêmen foram desprezados, colhendo-se o restante em Becker estéril protegido com gaze e garrafa térmica contendo água a $40^{\circ} \mathrm{C}$ (Figura 05).

$\mathrm{O}$ sêmen colhido foi avaliado quanto à contagem espermática, $\mathrm{pH}$ e motilidade. Posteriormente, este foi diluído com diluente comercial para Sêmen SUS-BTS ${ }^{3}$, mantido em banho-maria na temperatura de $37^{\circ} \mathrm{C}$, na proporção de $1: 10$.

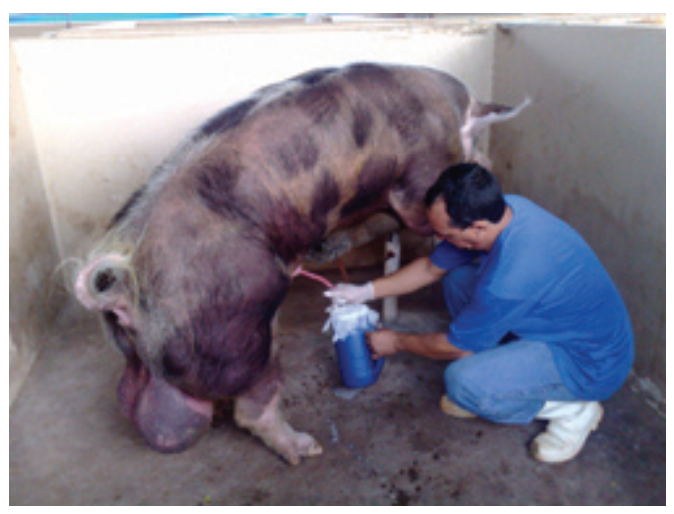

FIGURA 05: Procedimento de colheita de sêmen pelo método de massagem manual. Setor de Suinocultura Faculdade Dr. Francisco Maeda (FAFRAM) - Ituverava-SP, 2008.

\subsubsection{INSEMINAÇAO ARTIFICIAL}

A inseminação artificial foi realizada apenas nas marrãs. Estas foram submetidas ao mesmo procedimento de detecção de cio realizado para a monta natural, porém foram inseminadas por três vezes intervaladas de 12 horas (Figura 06).

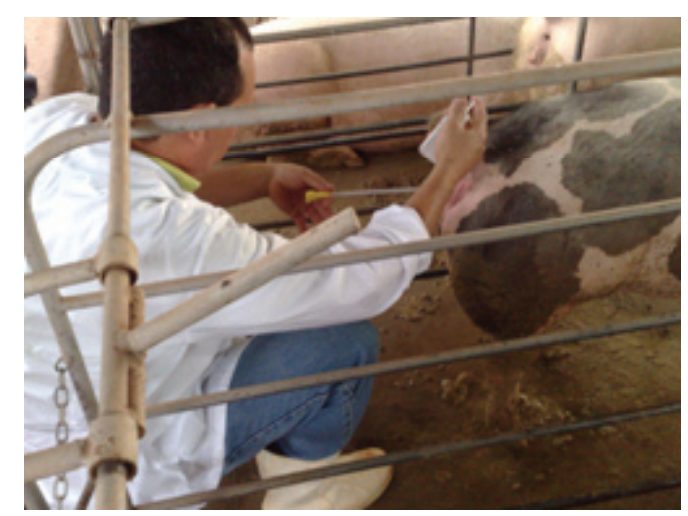

FIGURA 06: Procedimento de inseminação artificial em fêmea suína. Setor de Suinocultura - Faculdade Dr. Francisco Maeda (FAFRAM) - Ituverava-SP, 2008.

$3 \quad$ Majop Medi Chimica. 


\subsection{DIAGNÓSTICO DE GESTAÇÃO}

Os exames ultra-sonográficos foram realizados por ultra-sonografia transabdominal, utilizando-se aparelho Áquila Vet da Nutricell-Falcon ${ }^{\circledR}$, com transdutor convexo de $5,0 \mathrm{MHz}$ posicionado em ambos os antímeros.

Os animais foram mantidos em posição quadrupedal durante o exame (Figura 07), sendo utilizado gel a base de carboximetilcelulose (propagação do som). O diagnóstico positivo foi determinado pela visualização de vesículas gestacionais, representadas por estruturas anecóicas circulares, de contorno irregular, e a presença de embriões dentro das mesmas (Figura 08) e o diagnóstico negativo, determinado pela ausência dessas estruturas. As fêmeas cujos resultados foram negativos ou duvidosos, foram submetidas a novo exame 16 dias após o primeiro e o dia do acasalamento ou de inseminação artificial foi considerado o dia zero de gestação. Não houve preocupação com a determinação do número de fetos.

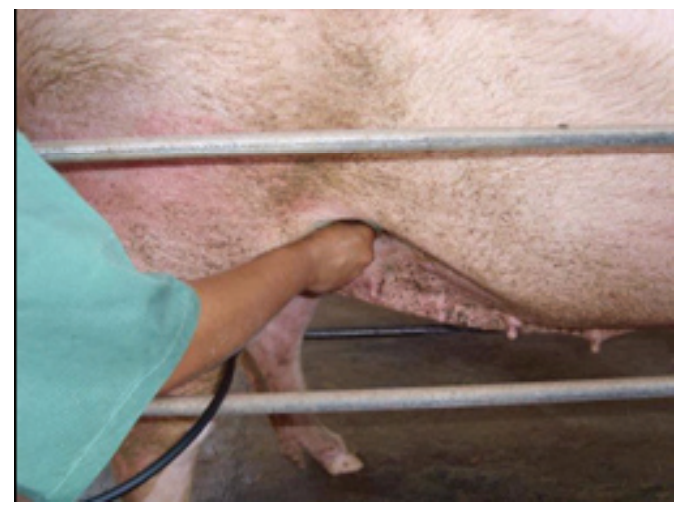

FIGURA 07: Posicionamento do transdutor para exame ultra-sonográfico transabdominal em fêmea suína mantida em posição quadrupedal. Setor de Suinocultura - Faculdade Dr. Francisco Maeda (FAFRAM) Ituverava-SP, 2008.

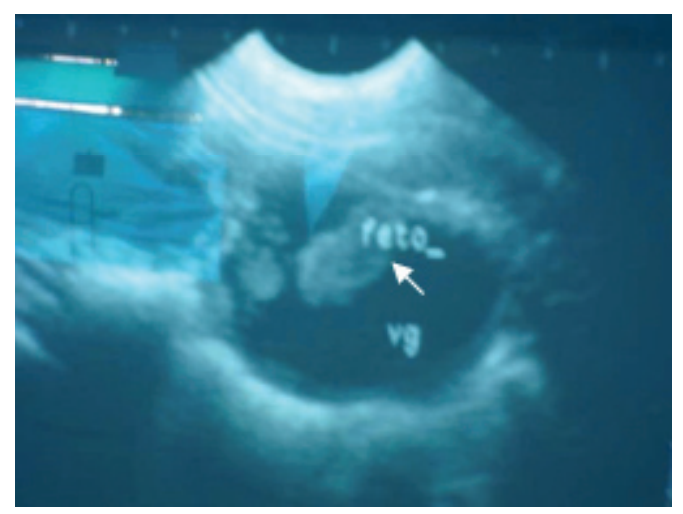

FIGURA 08: Imagem ultra-sonográfica da vesícula gestacional e feto (seta) em uma fêmea suína. Setor de Suinocultura - Faculdade Dr. Francisco Maeda (FAFRAM) - Ituverava-SP, 2008. 


\section{RESULTADOS E DISCUSSÃO}

Os resultados obtidos foram sumarizados na tabela 1. No primeiro dia da realização do exame ultra-sonográfico, foram examinadas 24 fêmeas, das quais cinco apresentavam 20 dias ou menos de tempo de gestação. Destas, quatro apresentaram resultados negativos ou duvidosos em relação ao diagnóstico de gestação, ou seja, não foi possível visualizar a presença de vesículas gestacionais (Figura 08). O tempo mínimo de gestação das fêmeas suínas para diagnóstico realizado por ultra-sonografia transabdominal foi de 20 dias.

O segundo exame foi realizado 16 dias após o primeiro, naquelas fêmeas com resultados negativos ou duvidosos, sendo que duas foram confirmadas prenhes e duas não prenhes.

Cortez et al. (2006) e Viana et al. (2001) relataram que a sensibilidade da técnica de ultrasonografia no diagnóstico de gestação em fêmeas suínas é a partir dos 21 dias de gestação. $\mathrm{O}$ presente trabalho está em concordância com a literatura consultada, quando se utiliza a técnica transabdominal.

Candini et al. (2000) afirmaram sobre a necessidade de proximidade da central de inseminação artificial da granja que a utilizará ou até mesmo sua implantação na própria granja, como uma limitação do uso desta técnica. Porém, esta limitação pode ser minimizada com o uso de diluentes comerciais para sêmen suíno, sendo que estes diluentes, por fornecerem nutrientes ao sêmen, mantêm maior viabilidade até em maiores distâncias, além de poder ser resfriado para manter essa viabilidade por até sete dias.

TABELA 1 - Diagnóstico de gestação através de ultra-sonografia transabdominal realizado em fêmeas suínas submetidas a acasalamento natural ou inseminação artificial. Setor de Suinocultura - Faculdade Dr. Francisco Maeda (FAFRAM) - Ituverava-SP, 2008. (continua)

\begin{tabular}{|c|c|c|c|c|c|}
\hline $\begin{array}{c}\mathrm{N}^{\circ} \\
\text { Animal }\end{array}$ & $\begin{array}{c}\text { Tipo de } \\
\text { acasalamento }\end{array}$ & $\begin{array}{c}\text { Data do } \\
\text { acasalamento }\end{array}$ & Data do exame & $\begin{array}{l}\text { Diagnóstico de } \\
\text { gestação }\end{array}$ & $\begin{array}{c}\text { Tempo de gestação } \\
\text { (dias) }\end{array}$ \\
\hline 1 & $\mathrm{AN}^{*}$ & $21 / 09 / 2008$ & $21 / 11 / 2008$ & Positivo & 62 \\
\hline 4 & AN & $24 / 09 / 2008$ & $21 / 11 / 2008$ & Positivo & 59 \\
\hline 5 & AN & $28 / 08 / 2008$ & $21 / 11 / 2008$ & Positivo & 86 \\
\hline 6 & $\mathrm{AN}$ & $24 / 08 / 2008$ & $21 / 11 / 2008$ & Positivo & 90 \\
\hline 7 & $\mathrm{IA}^{* *}$ & $21 / 11 / 2008$ & $21 / 11 / 2008$ & Negativo & 01 \\
\hline 9 & IA & $20 / 11 / 2008$ & $21 / 11 / 2008$ & Negativo & 02 \\
\hline 359 & IA & $10 / 11 / 2008$ & $21 / 11 / 2008$ & Negativo & 12 \\
\hline 361 & IA & $2 / 11 / 2008$ & $21 / 11 / 2008$ & Positivo & 90 \\
\hline 363 & IA & $25 / 10 / 2008$ & $21 / 11 / 2008$ & Positivo & 28 \\
\hline 368 & IA & $20 / 10 / 2008$ & $21 / 11 / 2008$ & Positivo & 33 \\
\hline 369 & IA & $11 / 11 / 2008$ & $21 / 11 / 2008$ & Duvidoso & 11 \\
\hline 573 & AN & $27 / 8 / 2008$ & $21 / 11 / 2008$ & Positivo & 87 \\
\hline 808 & AN & $4 / 09 / 2008$ & $21 / 11 / 2008$ & Positivo & 79 \\
\hline 830 & IA & $23 / 10 / 2008$ & $21 / 11 / 2008$ & Positivo & 30 \\
\hline 833 & IA & $18 / 10 / 2008$ & $21 / 11 / 2008$ & Positivo & 35 \\
\hline 862 & IA & $29 / 10 / 2008$ & $21 / 11 / 2008$ & Positivo & 24 \\
\hline 902 & $\mathrm{AN}$ & 08/10/2008 & $21 / 11 / 2008$ & Positivo & 45 \\
\hline
\end{tabular}


TABELA 1 - Diagnóstico de gestação através de ultra-sonografia transabdominal realizado em fêmeas suínas submetidas a acasalamento natural ou inseminação artificial. Setor de Suinocultura - Faculdade Dr. Francisco Maeda (FAFRAM) - Ituverava-SP, 2008. (conclusão)

$\begin{array}{cccccc}904 & \text { AN } & 8 / 10 / 2008 & 21 / 11 / 2008 & \text { Positivo } & 45 \\ 927 & \text { AN } & 25 / 08 / 2008 & 21 / 11 / 2008 & \text { Positivo } & 89 \\ 945 & \text { AN } & 3 / 09 / 2008 & 21 / 11 / 2008 & \text { Positivo } & 80 \\ 1140 & \text { AN } & 24 / 08 / 2008 & 21 / 11 / 2008 & \text { Positivo } & 90 \\ 1147 & \text { AN } & 13 / 08 / 2008 & 21 / 11 / 2008 & \text { Positivo } & 101 \\ 1222 & \text { IA } & 23 / 10 / 2008 & 21 / 11 / 2008 & \text { Positivo } & 30 \\ 1225 & \text { IA } & 28 / 10 / 2008 & 21 / 11 / 2008 & \text { Positivo } & 25 \\ 7 & \text { IA } & 21 / 11 / 2008 & 08 / 12 / 2008 & \text { Negativo } & 17 \\ 9 & \text { IA } & 20 / 11 / 2008 & 08 / 12 / 2008 & \text { Negativo } & 18 \\ 359 & \text { IA } & 10 / 11 / 2008 & 08 / 12 / 2008 & \text { Positivo } & 28 \\ 369 & \text { IA } & 11 / 11 / 2008 & 08 / 12 / 2008 & \text { Positivo } & 27\end{array}$

*AN: Acasalamento natural

**IA: Inseminação artificial

\section{CONCLUSÃO}

A técnica de ultra-sonografia para o diagnóstico de gestação em fêmeas suínas pode ser realizada com segurança a partir dos 20 dias de gestação, mostrando ser um exame rápido e de alta acurácia que pode ser utilizado nas criações tecnificadas como método auxiliar de contribuição na melhoria da eficiência reprodutiva nesta espécie.

\section{REFERÊNCIAS}

ALMEIDA, F.R.C.L., FOXCROFT, G. R. Manejo nutricional para fêmeas suínas de alta performance reprodutiva. In: REUNIÃO ANUAL DA SOCIEDADE BRASILEIRA DE ZOOTECNIA, 43, 2006, João Pessoa. Anais... João Pessoa: SBZ, 2006.

BORTOLOZZO, F. P.et al. Inseminação Artificial em Suínos. In: GONÇALVES, P. B. D.; FIGUEIREDO, J. R.; FREITAS, J. V. F. (Eds.) Biotécnicas aplicadas à reprodução animal. São Paulo: Varela, 2002. Cap.7, p.125-144.

CANDINI, P. H.et al. Comparação dos índices reprodutivos com inseminação artificial ou cobertura natural sob influências sazonais em suínos. Braz. J. Vet. Res. Anim. Sci., v. 37, n.6, 2000 . 
CAVALCANTI, S. S. et al. Diagnóstico precoce da gestação em porcas por palpação retal. Arquivo Brasileiro de Medicina Veterinária e Zootecnia, Belo Horizonte, v. 35, n. 1, p. 121$127,1983$.

CORTEZ, A. A.et al. Uso do eco-ultrassom, doppler e ultra-sonografia modo-B para o diagnóstico precoce de gestação em suínos. Ciênc. vet. tróp., Recife-PE, v. 9, n. 1, p. 9-16 jan./abr., 2006.

FERREIRA, F. M.et al. Comportamento de monta e características seminais de suínos jovens landrace e large white. Cienc. Rural, Santa Maria-RS. v. 35, n. 1, pp. 131-137, 2005.

FONTES, D. A.; MACHADO, G. S.; MENDES, C. B. S. Nutrição e eficiência reprodutiva de marrãs. In: SEMINÁRIO DE AVES E SUÍNOS, 7. AVESUI REGIÕES, 10 a 12 abr. 2007, Belo Horizonte. Anais...

FOXCROFT, G.R., AHERNE, F. Management of the gilt and first parity sow. In: SEMINÁRIO INTERNACIONAL DE REPRODUÇÃO E INSEMINAÇÃO ARTIFICIAL DE SUÍNOS, 7, 2000, Foz do Iguaçu. Anais... São Paulo, 2000, p. 99-105.

HUNTING, W. Pregnancy Diagnosis in Pigs. Veterinary Record, London, v. 90, p.139-144, 1972.

INABA, T.; NAKAZIMA, Y.; MATSUI, N. et al. Early pregnancy diagnosis in sows by ultrasonic linear electronic scanning. Theriogenology, Stoneham, v. 20, n.1, p.97-101, 1983.

OBERLENDER, G.; MURGAS, L. D. S.; MESQUITA, S. P. Inseminação Artificial em Suínos. Lavras, 2008. p.1-16. (Boletim Técnico, n. 79).

OLIVEIRA JUNIOR, A. R. Manejo de Reprodução em Suínos (Uso da Inseminação Artificial). Saúde Animal. Disponível em: <http://www.saudeanimal.com.br/artig100.htm>. Acesso em: 08 dez. 2008.

O'REILLY, P. J. Pregnancy diagnosis in pigs by ultrasonic amplitude depth analysis- a field evaluation. Irish Veterinary Journal, Dublin, v. 30, p. 165-167, 1976.

SILVA, D. M.; MURGAS, L. D. S.; ALVARENGA, A. L. N. Manejo da cobrição da suinocultura. Lavras, 2008. p. 1-13. (Boletim Técnico, n. 80)

SILVA, M. C. et al. Técnicas simples para a detecção de prenhez na porca. Revista Brasileira 
de Reprodução Animal, Belo Horizonte, v. 25, n. 3, p. 448-449, 2001.

TONIOLLI, R.; DANTAS, K. S. A.; MESQUITA, D. S. M. Diagnóstico precoce da gestação por palpação retal, biópsia vaginal e ultrassom na espécie suína. Boletim de la Sociedad Veterinaria Venezolana de Especialistas em Cerdos, v. 4, n.1 e 2, p.78, 1989.

ULTRA-SONOGRAFIA em suínos entusiasma produtores do setor. Universidade do Oeste de Santa Catarina: Notícias, 02 set. 2008. Disponível em: http://www.unoescxxe.edu.br/unoesc/ noticias_unoesc/desc_noticias.php?cod_noticia $=660$. Acesso em: $08 \mathrm{dez} .2008$.

VIANA, C. H. C.et al. Comparação entre as técnicas de ultra-sonografia e Doppler com relação à eficiência no diagnóstico de gestação em fêmeas suínas. In: CONGRESSO BRASILEIRO DE VETERINÁRIOS ESPECIALISTAS EM SUÍNOS, 10. Anais... Porto Alegre: Abraves, 2001. v. 1 , p. $185-186$.

VIANA, C. H. C.et al. Avaliação do desempenho da técnica de ultra-sonografia, para o diagnóstico precoce de gestação, em fêmeas suínas. In: CONGRESSO BRASILEIRO DE VETERINÁRIOS ESPECIALISTAS EM SUÍNOS, 10. Anais... Porto Alegre: Abraves, 2001. v. 2 , p. $187-188$. 